\title{
Eğitimcilerin Gözünden Türk Eğitim Sistemi: Bir Metafor Çalışması*
}

\section{Ahmet SAYLIK ${ }^{* *}$, Numan SAYLIK ${ }^{* * *}$,Abdulkadir SAĞLAM ${ }^{* * * *}$}

Öz: Bu araştırmanın amacı, akademisyenlerin ve öğretmenlerin Türk eğitim sistemine ilişkin algılarını metaforlar aracılığıyla ortaya koymaktır. Araştırmanın verileri, 2018-2019 bahar döneminde Van Yüzüncü Yıl Üniversitesi Eğitim Fakültesi'nde görev yapan dokuz akademisyen ile Van ili İpekyolu, Tuşba ve Edremit ilçelerinde anaokulu, ilkokul, ortaokul ve lise kademelerinde görev yapan 54 öğretmenden toplanmıştır. Araştırmada, nitel araştırma yöntemi kullanılmış, olgubilim (fenomenoloji) araştırmanın deseni olarak seçilmiştir. Toplanan veriler içerik analizi yöntemi ile çözümlenmiştir. Eğitimciler, Türk eğitim sistemini yapboz, bukalemun, yazboz tahtası, fabrika, makine gibi metaforlarla açıklamıştır. Eğitimcilerin oluşturduğu metaforlar reformların sıklığı ve uzun vadeli sonuç üretememesi, körelticilik, karmaşık ve girift yapı, tektipleştiricilik kategorileri altında toplanmıştır. Ayrıca Türk eğitim sisteminin nasıl olması gerektiği konusunda eğitimciler, asırlık çınar, sağlam bir bina, Finlandiya eğitim sistemi, bina temeli, anne, su gibi metaforlar üretmişlerdir. Bu metaforlar ise devamlılık ve sağlamlık, bireyselleştiricilik, yararlılık, özgürleştiricilik, ahenklik gibi kategoriler altında toplanmıştır. Araştırma sonucunda eğitimcilerin Türk eğitim sisteminin sık sık değişikliğe uğradığı, karmaşık bir yapıda olduğu, bireyi köreltici ve tektipleştirici bir sistem olduğu yönünde bir algıya sahip oldukları tespit edilmiştir. Öte yandan Türk eğitim sisteminin devamlılığı ve sağlam yapıda olmasının yanında sistemin yararlı, bireyselleştirici ve özgürleştirici olması gerektiği vurgusu öne çıkmaktadır. Eğitim sisteminde yapılan değişikliklerin uzun erimli olmaması, söz konusu değişikliklerin eğitimciler tarafından benimsen(e)memesine yol açmaktadır. Yapılan değişikliklerin sonuçlarının görülmeden yeni değişikliklere gidilmesinin eğitimde devamlılığın yitirilmesi algısını doğurması, araştırmanın bir diğer sonucudur.

\footnotetext{
* Çalışma. 11-13 Mayıs 2018 tarihinde düzenlenen 12. Uluslararası Eğitim Yönetimi Kongresinde sunulan "Yapboz mu asırlık çınar mı? Eğitimcilerin gözünde Türk Eğitim Sistemi” isimli sözlü bildirinin genişletilmiş halidir.

**Dr. Öğr. Üyesi Siirt Üniversitesi, Eğitim Fakültesi, Eğitim Bilimleri Bölümü, Email:ahmetsaylik@gmail.com Orcid No: 0000-0001-7754-2199

*** Doktora Öğrencisi, Hacettepe Üniversitesi, Eğitim Bilimleri Enstitüsü, Email: nmnsylk@gmail.com, Orcid No: 00000003-3551-1903.

**** Doktora Öğrencisi, Hacettepe Üniversitesi, Eğitim Bilimleri Enstitüsü, Email: saglam6888@gmail.com, Orcid No: 0000 000330235751.
} 
Anahtar Kelimeler: Türk Eğitim Sistemi, Metafor, Eğitim, Olgubilim.

\section{Turkish Education System from the Perspective of Educators: A Metaphor Analysis}

Abstract: This study aims to reveal the perceptions of academics and teachers about the Turkish education system through metaphors. The data of the study were collected from nine academics working in Van Yüzüncü Y1l University Faculty of Education and 54 teachers working in kindergarten, primary school, middle school, and high school levels in İpekyolu, Tuşba and Edremit districts of Van province during the spring term of 2018-2019. In the research, qualitative research method was used and the phenomenology was seleceted as the research design. The collected data were analyzed using the content analysis method. Educators explain the Turkish education system with metaphors such as puzzle, chameleon, everchanging, factory, and machine. The metaphors created by educators were collected under categories of reforms and failure to produce, inability to produce long-term results, blunting, complex and intricate structure, and standardizing. In addition, educators produced metaphors about the ideal Turkish education system with terms such as a century-old plane tree, a solid building, the Finnish education system, groundwork, mother, and water. These metaphors, on the other hand, were collected under categories such as continuity and durability, individualization, usefulness, emancipatory, and harmony. As a result of the research, it was determined that the educators possess a perception revealing that the Turkish education system has been subjected to frequent changes and has a complex structure, and is a system that dulls and homogenizes the individual. Since the changes made in the education system are not longterm, they are not easily adopted by educators. Another result of the research is that making new changes without coming through the results of such changes leads to the perception of losing continuity in education.

Keywords: Turkish education system, metaphor, phenomenology 


\section{Giriş}

Eğitim, hem kişinin yaşamını düzenleyen bir süreç hem de toplumsal yapıyı düzenleyen önemli bir sistemdir. En geniş anlamda sosyalleşme ile benzer anlamda kullanılan eğitim, kişinin yaşamı süresince doğrudan ya da dolaylı olarak etkilendiği bir alan olarak ortaya çıkmaktadır. Aynı zamanda eğitim, kişinin sosyal yaşamda aktifleşmesini ve birey olmasını destekleyen önemli unsurlardan biridir. Günümüz dünyasında bilgi önemli bir hazinedir ve bu bilginin bireysel, ulusal ve evrensel gelişiminin ana unsurunu eğitim oluşturmaktadır. Eğitimi her yönüyle değerlendiren, bilgi ve bilim toplumu olma gayretindeki sosyal gruplar, uluslar veya medeniyetler; kolektif bir gelişim göstermeyi amaçlamaktadırlar.

Eğitimde modernleşme, düzenleme, reform veya kalite arayışları odaklı çalışmaların temeli, geçmiş ile şimdiki eğitim sistemlerinin değerlendirilerek, günümüz eğitim paradigmaları 1şığındaki yönelimlerin belirlenmesine dayanmaktadır. Değerlendirmeler sonucunda, eğitim sistemine yön verecek yeni fikirlerin belirlenerek eğitim-öğretim çalışmalarında yer verilmesi gerektiği belirtilmektedir (Türk, 2003).

Eğitim sistemi, belirli amaçlar doğrultusunda okulöncesi, ilköğretim, ortaöğretim ve yükseköğretim alt sistemleri aracılı̆̆ı ile bütünleşmiş bir yapıdadır. Eğitim kalitesini ve verimliliği yükseltmek adına eğitim sistemimizde Avrupa Birliği eğitim politikaları takip edilmektedir (Sağlam, Özüdoğru ve Çıray, 2011). Türk eğitim sistemin (TES) Avrupa Birliğine uyum süreci kapsamında birtakım iyileştirme ve geliştirme çalışmalarına tabi tutulmaktaysa da halen çözüm bekleyen birtakım sorunlar söz konusudur.

Yı1maz ve Altınkurt (2011) 91 öğretmen adayıyla tarama modelinde gerçekleştirdiği çalışmalarında TES'in en temel sorunlarını merkezi sınavlar, kalabalık sınıflar, ezberci eğitim, donanım ve fiziki yapı eksikliği, mevcut öğretmenlerin niteliği, eğitime erişimdeki eşitsizlikler, siyaset (ideolojik ayrım ve kayırmalar), öğretmen atama sistemi, özel dershaneler, finansman ve mesleki teknik eğitim sorunları olarak bulgulamışlardır.

Taşdemir (2015), Türk Milli Eğitiminin mevcut yapısı içerisindeki sorunları tespit etmek amacıyla gerçekleştirdiği çalışmasında 69 öğrenciden görüşme formu aracılığıyla veriler toplamıştır. Taşdemir (2015) çalışmasının sonucunda sistemin sürekli değişmesi, öğretmenlerin niteliksizliği, programların yapısı, ezbere dayalı eğitim, bölgeler arası eğitim eşitsizliği, tek tip insan yetiştirme, sınav odaklı eğitim, okulların cazip olmaması, verilen eğitimin yetersizliği, öğretmen öğrenci ilişkilerindeki bozulma, özel ve devlet okullarının farklı eğitim vermesi, kalitesiz eğitim, rehberlik hizmetlerinde yetersizlik, mesleki eğitime önem vermeme, okul aile ilişkisi, eğitimin yönetimi, karma eğitim, başarı değerlendirmesi, kitap kullanımı, spor ve 
engellilere önem vermeme, zorunlu din eğitimi, burs desteği, okul güvenliği, yabancı dil öğretimi, okul kontenjanları sorunlarını tespit etmiştir.

Kutlu Abu, Bacanak ve Gökdere (2016), Amasya Üniversitesi’nde öğrenim görmekte olan 5 öğretmen adayı ile gerçekleştirdikleri çalışmada TES'in sorunlarını çocukların alt kademelerden itibaren ilgi ve yeteneklerinin keşfedilip devam ettirilmemesi, öğretmen, akran gruplar, aileler ya da yöneticilerden oluşan mentorların bulunmaması, zenginleştirilmiş etkinliklerin bulunmaması, emekli olmayan öğretmenlerin fazlalığı, okulöncesi eğitim almayan öğrencinin çeşitli alt yapı sorunları, öğretmen niteliksizliği, öğretmen ataması olarak belirlemişlerdir.

Özdemir ve Kaplan (2017) çalışmalarında 68 matematik öğretmeni adayıyla görüşmüş ve TES 'in sorunlarını tespit etmeye çalışmışlardır. Araştırma sonucunda TES'in sürekli değişen eğitim sistemi, ezberci eğitim, altyapı eksikliği, öğretmenlerin yetiştirilmesi ve eğitimi şeklindeki sorunlara sahip olduğu ileri sürülmüştür. Çözüm yolu olarak ise öğretmen adayları çoğunlukla; öğretmenlerin yetiştirilmesinde düzenlemeler yapılmalı, uygulamaya yönelik eğitim yapılmalı, ezbercilikten kaçınılmalı, eğitim sistemi sürekli değişmemeli ve liyakat sağlanmalı şeklinde görüş belirtmişlerdir.

Alanyazın incelendiğinde; TES'in sorunlarından bazılarının öğretmen niteliğinden kaynaklanan yetersizlikler, toplumsal değer yargılarının engelleyici etkileri, cinsiyet, bölgesel dağılım ve irksal eşitsizlikler, kaynak yetersizliğinden kaynaklanan fiziki yetersizlikler, küreselleşme ve bütünleşme adına milli bir eğitim politikasından uzaklaşma şeklinde pek çok sorun ortaya konulmuştur (Gelbal ve Kelecioğlu, 2007; Habacı, Karataş, Adıgüzelli, Ürker ve Atıcı, 2013; Taşgın ve Sönmez, 2013; Uğurlu, Kıral ve Kıral, 2011). Ankara Üniversitesi Çalıştay Raporu'nda (2004) okulöncesi ve ilköğretim eğitim sorunları tartışılmış, personel ve öğretmen yetiştirme, yönetim, altyapı donanım, mimari yapı eksikliği, denetim eksikliği, yönlendirme, bir üst kademeye geçişte sorunlar, program eksiklikleri, ödenek sorunları, taşımalı eğitim sorunları, okul aile ile ilgili çeşitli sorunlar tespit edilmiştir.

TES'in sorunlarını ortaya koymaya yönelik olarak yapılan çalışmalara bakıldığında; sistemin içerisinde aktif olarak yer alan öğretmenler ile akademisyenlerin bir arada görüşlerini ortaya koyan bir çalışmaya rastlanılamamıştır. Sisteme dair çıktılar, sistemin içerisinde aktif olarak yer alan eğitim çalışanlarından alınan dönütler ve sistemin sonunda elde edilen ürünlerin değerlendirilmesi ile elde edilebilir. Sistemin bileşenlerinden olan üniversitelerin eğitim fakültelerinde görev yapan akademisyenler ile okullarda görev yapmakta olan öğretmenlerden alınan dönütlerin, uygulayıcılar ve araştırmacılar için yol gösterici olabileceği düşünülmektedir. 
Araştırma, akademiysen ve öğretmenlerin TES'e ilişkin algılarını metaforlar aracılığıyla incelemeyi amaçlamaktadır. Bu genel amaç doğrultusunda aşağıdaki sorulara yanıt aranmıştır: Kat1lımciların,

1. Mevcut durumda Türk Eğitim Sistemine ilişkin görüşleri nasıldır?

2. Türk Eğitim Sistemine ilişkin ideal görüşleri nasıldır?

\section{Yöntem}

\section{Araştırmanın Deseni}

Araştırma, nitel araştırma yöntemlerinden biri olan olgubilim (fenomenoloji) ile desenlenmiştir. Olgubilim (fenomenoloji/phenomology) deseni, derinlemesine ve ayrıntılarına hakim olunmayan, tam anlamıyla kavranmayan ancak farkında olunan olgular, olay ve deneyimlere, algılara, yönelim, kavram ve durumlara odaklanan bir araştırma yaklaşımıdır (Yıldırım ve Şimşek, 2008). Patton'a (2002) göre ise olgubilim, insanların deneyimi anlamlandırma şeklini ve gerek bireysel gerekse paylaşılan anlam olarak deneyimi bilince dönüştürme şekillerini keşfetme üzerine odaklanmaktadır.

Çalışmada verilerin elde edilmesi adına metafor tekniği kullanılmıştır. "İnsanlar, bir düşünceyi veya duyguyu ifade ederken, onu karşısındaki kişi ya da kişilerin anlayabileceği bir yapıya dönüştürmek zorundadır" (Pratte, 1981, s.310). Soyut ifadelerin anlaş1labilmesi için somut hale dönüştürülmesi gereklidir. Somutlaştırmalar ise kişilerin tecrübeleriyle paralellik göstermektedir. Metaforlar da soyut kavramların somutlaştırılmasında kişilerin başvurduğu vazgeçilmez araçlardan biridir.

Metafor kelimesi, Yunancada yer alan "Metapherein” sözcüğünden türemiştir. Meta, bir şeyi değiştirmek anlamında iken ve pherein ise taşımak anlamına gelmektedir. Bu yönüyle düşünüldüğünde metaforlar, bilinen bir alandan az bilinen veya hiç bilinmeyen yeni bir alana bilgi transfer etme, taşımadır (Aydoğdu, 2008; Yapıcı, 2015). Bu bilgi taşımanın temelinde benzetme vardır. Metaforlar birbirinden farklı olan iki fenomeni, bilinenden bilinmeyene ve somut olandan soyut olana doğru benzetmeler kullanılarak anlaşılırlığı daha güçlü hale getirmede önemli rol oynarlar. Başka bir ifadeyle metaforlar yeni bilgilerin eski bilgilerle benzer yanlarını belirleyerek bu iki bilgi arasında ilişki kurmasını sağlar. Böylece yeni bilginin somut bir şekilde ifade edilmesine yardımcı olur (Senemoğlu, 2007). Balcı (2006), bu yolla karmaşıklığı ve soyutu farklı bakış açılarından, (lenslerden) görme olanak sağlandığını belirtir.

Eğitimde kavram kargaşalarını ayırt edebilen metaforlar, doğru olan bilgileri gün yüzüne çıkarma gücüne de sahip bir araçtır. Metafor kullanma esnasında kişiler, deneyimleriyle 
yaşantıları arasında bir bağ kurarak farkında olarak veya olmayarak doğruları söyleme yönelimindedirler (Lakoff ve Johnson, 2003). Metaforların fonksiyonu, “anlamak” olduğundan eğitim ve öğretim faaliyetlerinde algılamanın bir yöntemi olarak da ele alınmaktadır (Woon ve Ho, 2005). Eğitimde doğru bilgi ve kavramları belirleme ve öğretme yetisine sahip bir araç olan metaforlar, son y1llarda gerçekleştirilen bilimsel çalışmalarda yeni bir araştırma yöntemi olarak kullanılmaktadır.

\section{Çalışma Grubu}

Çalışma grubu, amaçlı örnekleme türlerinden maksimum çeşitlilik örnekleme yöntemiyle belirlenmiştir. Maksimum çeşitlilik örnekleme yönteminde hedeflenen, göreli olarak küçük bir örneklem oluşturmak ve bu örneklemde çalışılan probleme taraf olabilecek bireylerin çeşitliliğini maksimum derecede yansıtmaktır. Burada bu çeşitliliği sağlamada amaç, genellemeye ulaşmak değildir; aksine çeşitlilik gösteren durumlar arasında herhangi ortak ya da paylaşılan olguların olup olmadığını bulmaya çalışmak ve bu çeşitliğe göre problemin farklı boyutlarını ortaya koymaktır (Yıldırım ve Şimşek, 2008). Patton’a (1987) göre ise maksimum çeşitlilik gösteren küçük bir örneklemin en az iki yararı vardır. Bunlar; örnekleme dâhil her durumun kendine özgü boyutlarının ayrıntılı bir biçimde tanımlanması ve büyük ölçüde farklı özellik gösteren durumlar arasında ortaya çıkabilecek ortak temaların ve bunların değerinin ortaya çıkarılmasıdır.

Araştırmaya Van ili İpekyolu, Tuşba ve Edremit merkez ilçelerindeki 25 okuldan 54 öğretmen (16 farklı branştan) ile Van Yüzüncü Yıl Üniversitesi Eğitim Fakültesinden 9 akademisyenin dâhil edilmesiyle maksimum çeşitlilik örneklemesine ulaşılmaya çalışılmış, neticede 63 eğitimcinin katılımı sağlanmıştır.

\section{Veri Toplama Aracı ve Süreci}

Araştırma kapsamında veriler, sözlü iletişim yoluyla veri toplama yaklaşımı olan görüşme tekniği ile toplanmıştır. Görüşmede katılımcıların söylemlerinin yüzeysel anlamlarının ötesinde söylemin doğrudan ifadesi ve derinliği de ortaya çıkarılabilmektedir. Bununla birlikte verilen yanıtlardaki gerçek dışı ya da sahte ifadelerin de fark edilme olasılığ yüksektir. Araştırmacı, görüşme esnasında karşılaştığı her karanlık noktayı, soracağı sorularla aydınlatma olanağına sahip olmaları, görüşmede, ses tonu, mimikler ve soruları cevaplandırma şekilleri, söylenenleri anlamlandırmada önemli ipuçları (Karasar, 2016) sağlamaktadır.

Araştırmada veri toplama aracı olarak araştırmacılar tarafından geliştirilen yarı yapılandırılmış taslak form uzman görüşleri alınarak oluşturulduktan sonra, araştırmaya dâhil edilmeyen 6 eğitimci ile pilot uygulaması yapılmıştır. Veri toplama sürecinde katılımcıların 
rızası aranmış, çalışmanın amacı açıklanmış ve 10-15 dakikalık bir zaman diliminde görüşmeyi tamamlayacakları ifade edilmiştir. Veriler, katılımcıların kişisel bilgi formu ile cümle tamamlama aracılığıyla TES hakkındaki metaforlarını ifade ettikleri bir soru formu aracılığı ile toplanmıştır. Uygulama esnasında katılımcılara metaforun tanımı ile ilgili bilgi verilmiş, onların araştırmanın amaçlarına yönelik olarak sahip oldukları metaforları ortaya çıkarmak için her bir katılımcı akademisyen ve öğretmene yöneltilen; “Türk eğitim sistemi benzer. Çünkü........" ve "Türk eğitim sistemi gibi olmalıdır. Çünkü .." sorularina verdikleri yanıtlardan elde edilen metaforlar ile veriler toplanmıştır. Akademisyen ve öğretmenlerden yukarıdaki ifadede boş bırakılan yerleri kullanarak ve tek bir metafor üzerinde odaklanmaları ve düşüncelerini ifade etmeleri istenmiştir. Araştırma boyunca bir araştırmacının görüşmeleri kayıt altına alacağı katılımcılara ifade edilmiştir.

\section{Verilerin Çözümlenmesi}

Yarı yapılandırılmış görüşme formuyla elde edilen veriler içerik analizi ile çözümlenmiştir. içerik analizinde temel amaç, toplanan verileri açıklayabilecek kavramalara ve ilişkilere ulaşmak, birbirine benzeyen verileri belirli kavramlar ve temalar çerçevesinde bir araya getirmek ve bunları okuyucunun anlayabileceği bir biçimde organize ederek yorumlamaktır (Yıldırım ve Şimşek, 2008). Bu bağlamda başlangıçta bir araya getirilen verilere, üç araştırmacı tarafından iki ayrı kodlama yapılmıştır. Sonraki aşamada kodlanan veriler, oluşan temalar ve alt temalar altına yerleştirilmiştir. Son olarak elde edilen temalar üzerinde üç araştırmacı uzlaştıktan sonra kodlayıcılar arasındaki güvenirlik analizinin gerçekleştirilmesi için eğitim bilimleri ve nitel araştırma konularında bir uzmanın görüşüne sunulmuştur. $\mathrm{Bu}$ işlemde görüş birliği ve görüş ayrılığı sayıları belirlenerek araştırmanın iç güvenirliği, Güvenirlik=[Görüş Birliği / (Görüş Birliği + Görüş Ayrıllı̆̆ı)] X 100 formülasyonu kullanılarak .90 olarak hesaplanmıştır. Uzman ve araştırmacı değerlendirmeleri arasındaki uyumun \%90'a yaklaşması durumunda arzu edilen düzeyde bir güvenirlik sağlanmış olmaktadır (Miles ve Huberman, 2014). Bu bilgiler 1şı̆̆ında, çalışmanın güvenirliği ile ilgili elde edilen bulguların yeterli düzeyde olduğu belirlenmiştir. Katılımcılar cinsiyet ve katılımcı numaralarına göre E1, E2, E3,....E63 şeklinde kodlanmıştır.

\section{Geçerlik ve Güvenirlik}

Nitel araştırmaların sonuçlarının inanırlığı, araştırmanın güvenirlik ve geçerliğinin ne kadar sağlandığı ile doğrudan ilişkilidir (Yıldırım ve Şimşek, 2008). Bu kapsamda veri toplama aracı, araştırmanın amaçları doğrultusunda, alanyazın taramasıyla desteklenerek ve uzman görüşüne başvurularak hazırlanmış, ana uygulamaya geçmeden önce ön uygulama yapılmış 
böylece ölçme aracının ölçülmek istenen amaca hizmet etmesi sağlanmıştır. Öte yandan verilerin analizi detaylı biçimde açıklanmış, bulguların kaynağının yalnızca katılımcıların metafor cümleleri olmasına özen gösterilmiş ve katılımcıların ifadelerinden doğrudan alıntılara yer verilmesi suretiyle geçerlik sağlanmaya çalışılmıştır. Araştırmanın geçerliğine ilişkin belirtilen hususlar veri toplama aracı ve süreci ile verilerin analizi başlıkları altında detaylı bir biçimde açıklanmıştır.

Araştırmanın güvenirliği sağlamak için ise veri kaynağı olan öğretmen ve akademisyenlerin kişisel bilgilerine yer verilmiştir. Eğitim yönetimi alan uzmanı iki akademisyenin, metaforların belirlenen kategorileri temsil edip etmemesi konusunda görüşlerine başvurulmuş, çalışma bu doğrultuda yürütülmüştür. Araştırmanın iç güvenirliği, bütün araştırmacıların araştırmanın bütün aşamalarında birlikte çalışması, görüş birliği ve ayrılığına ilişkin hesaplamalar yapılması ile sağlanmıştır.

Nitel araştırmalarda sonuçların diğer kişilere ya da durumlara aktarılabilirliği de önemli bir husustur (Guba ve Licoln, 1982). Bunu sağlamanın en önemli yolu örnekleme türü, örnekleme almanın ayrıntılı biçimde verilmesi ve örneklemin kabul edilebilir büyüklükte olmasıdır. Bu konuda alınan tedbirler, çalışma grubu başlığı altında ayrıntılı biçimde verilmiştir.

\section{Bulgular}

$\mathrm{Bu}$ bölümde araştırma bulguları akademisyen ve öğretmenlerden oluşan toplam 63 katılımcının TES'in ne olduğu ve ne olması gerektiğine ilişkin oluşturdukları metaforlar, tema ve alt tema olarak sunulmuştur. Araştırmada katılımcıların önemli olduğu düşünülen görüşlerinden örnekler, birebir alıntılanarak bulgular bölümünde verilmiştir. Ayrıca, katılımcıların kullandığı metaforlar ile tema ve alt temaların hangi sıklıkta tekrar ettiği (frekans) tablolaştırılmıştır. Takip eden bölümde, katılımcıların görüşlerini vurgulamak amacıyla, iki araştırma sorusunun etrafında oluşan tema ve alt temalar rapor edilmiştir.

Katılımcıların Türk eğitim sisteminin mevcut durumuna ilişkin oluşturdukları metaforlar Tablo 1'de verilmiştir.

Tablo 1: Katılımcıların TES'in mevcut durumunu neye benzettiklerine ilişkin oluşturdukları metaforlar

\begin{tabular}{llllll}
\hline $\begin{array}{l}\text { S. } \\
\text { No }\end{array}$ & Oluşturulan Metafor & f & $\begin{array}{l}\text { S. } \\
\text { No }\end{array}$ & Oluşturulan Metafor & f \\
\hline 1 & Yapboz & 7 & 25 & Gelişmeye aday bir şehir & 1 \\
\hline 2 & Bukalemun & 7 & 26 & Kaldırım taşı & 1 \\
\hline 3 & Yazboz Tahtası & 3 & 27 & Mevsimlik meyve & 1 \\
\hline 4 & Kervansaray & 2 & 28 & Çocuk & 1 \\
\hline 5 & Fabrika & 2 & 29 & Rotasız gemi & 1 \\
\hline
\end{tabular}


YYÜ Eğitim Fakültesi Dergisi (YYU Journal of Education Faculty), 2021; 18(1)522-546,http://efdergi.yyu.edu.tr,

\begin{tabular}{llllll}
\hline 6 & Çuval & 1 & 30 & Türk dizilerine & 1 \\
\hline 7 & Turşu & 1 & 31 & Çocuk oyuncağı & 1 \\
\hline 8 & Makine & 1 & 32 & Bumerang & 1 \\
\hline 9 & Yanmış yemek & 1 & 33 & Yemek & 1 \\
\hline 10 & İp yumağı & 1 & 34 & Doğanın oluşumu & 1 \\
\hline 11 & Lokomotif & 1 & 35 & Hasarlı bir binaya & 1 \\
\hline 12 & Sürekli duran araba & 1 & 36 & İnşaat & 1 \\
\hline 13 & Hazır yemek & 1 & 37 & Okyanus dalgasına & 1 \\
\hline 14 & Yüksek kalorili yemek & 1 & 38 & Deneme tahtası & 1 \\
\hline 15 & Pavlov'un köpeği & 1 & 39 & Düzeni kaçmış fabrikaya & 1 \\
\hline 16 & Bürokratik süreç & 1 & 40 & Pankreas kanseri olmuş birine & 1 \\
\hline 17 & Dart tahtası & 1 & 41 & Koşu bandına & 1 \\
\hline 18 & Disiplinsiz kışla sistemi & 1 & 42 & Amaçsız bir topluluk & 1 \\
\hline 19 & Papağan & 1 & 43 & Tutmayan cıvata & 1 \\
\hline 20 & Bilginin sayılarla ifade edildiği bilgi & 1 & \multirow{2}{*}{44} & \multirow{2}{*}{ Ne yapacağını bilmeyen bir adama } & 1 \\
& yarışı & & & & 1 \\
\hline 21 & Bisiklet sürücüsünün kullandığ tank & 1 & 45 & Ayarsız makas & 1 \\
\hline 22 & Torna Tezgahı & 1 & 46 & Ezberci eğitim sistemi & \\
\hline 23 & Kanserli bir vaka & 1 & 47 & Mehteran & \\
\hline 24 & Arapsaçı & 1 & & & \\
\hline
\end{tabular}

Tablo 1 incelendiğinde 63 eğitimcinin 47 farklı metafor ürettikleri görülmektedir. En sık kullanılan metaforlar "bukalemun" ve "yapboz" olmakla birlikte "Kervansaray, Fabrika, Yazboz tahtası" da birden fazla kişinin kullandığı metaforlardır. Ayrıca 42 metafor yalnızca tek bir katılımcı tarafından kullanılmıştır.

Katılımcıların idealde Türk eğitim sistemine yönelik oluşturdukları metaforlara Tablo 2'de yer verilmiştir.

Tablo 2: Katılımcıların TES’nin neye benzemesi gerektiğine ilişkin oluşturdukları metaforlar

\begin{tabular}{|c|c|c|c|c|c|}
\hline $\begin{array}{l}\text { S. } \\
\text { No }\end{array}$ & Oluşturulan Metafor & $\mathbf{f}$ & $\begin{array}{l}\text { S. } \\
\text { No }\end{array}$ & Oluşturulan Metafor & $\mathbf{f}$ \\
\hline 1 & Asırlık çınar & 7 & 25 & Planlı & 1 \\
\hline 2 & Sağlam bir bina & 4 & 26 & Kültürel sermaye & 1 \\
\hline 3 & Finlandiya eğitim sistemi & 3 & 27 & Uzay mekiği & 1 \\
\hline 4 & Bina temeli & 2 & 28 & Yeni yapılan bir bina & 1 \\
\hline 5 & Anne & 2 & 29 & İyi ayarlanmış makas & 1 \\
\hline 6 & Hayat & 2 & 30 & Dünya vatandaşı & 1 \\
\hline 7 & Orman & 2 & 31 & Ahtapot & 1 \\
\hline 8 & $\mathrm{Su}$ & 2 & 32 & Sevgi & 1 \\
\hline 9 & $\begin{array}{l}\text { Ekolojik dengenin olduğu bir } \\
\text { sistem }\end{array}$ & 1 & 33 & Keyif alınan bir oyun & 1 \\
\hline 10 & İnsan & 1 & 34 & Haciyatmaz & 1 \\
\hline 11 & Uyumlu dişlilerden oluşan saat & 1 & 35 & Yapılandırmacı ve devlet politikası & 1 \\
\hline 12 & Sağlıklı bir insan vücudu & 1 & 36 & İnsan metabolizmas1 & 1 \\
\hline 13 & Çocukların dostu & 1 & 37 & İşlevsel & 1 \\
\hline 14 & Güneş & 1 & 38 & $\begin{array}{l}\text { Formula sürücüsünün kullandığı } \\
\text { arazi arac1 }\end{array}$ & 1 \\
\hline 15 & $\begin{array}{l}\text { Farklı tatların ortaya çıtığ } 1 \text { bir } \\
\text { mutfak }\end{array}$ & 1 & 49 & $\begin{array}{l}\text { Avrupa Birliği üyesi ülkelerin eğitim } \\
\text { sistemi }\end{array}$ & 1 \\
\hline 16 & Berrak bir su & 1 & 40 & Parmak izi & 1 \\
\hline
\end{tabular}




\begin{tabular}{|c|c|c|c|c|c|}
\hline 17 & Kale & 1 & 41 & Bir ağacın dalları & 1 \\
\hline 18 & Güçlü bir birey & 1 & 42 & Osmanlı'nın ilk yılları & 1 \\
\hline 19 & Soluksuz bir roman & 1 & 43 & Araştırıc1- Deneyimleyici & 1 \\
\hline 20 & Çocuk & 1 & 44 & Ar1 & 1 \\
\hline 21 & Bir ağacın büyümesi & 1 & 45 & $\begin{array}{l}\text { Yaşadığ } 1 \text { çevreye adapte olabilen } \\
\text { canlılar }\end{array}$ & 1 \\
\hline 22 & $\begin{array}{l}\text { Öğretmenin daha fazla merkezde } \\
\text { olduğu bir sistem }\end{array}$ & 1 & 46 & Geri dönüşüm & 1 \\
\hline 23 & Fabrika & 1 & 47 & Bilim & 1 \\
\hline 24 & $\begin{array}{l}\text { Avrupa'nın oturmuş eğitim } \\
\text { sistemi }\end{array}$ & 1 & & & \\
\hline
\end{tabular}

Katılımcıların idealde Türk eğitim sistemine yönelik oluşturdukları metaforlar incelendiğinde 63 eğitimcinin 47 farklı metafor geliştirdiği görülmektedir. "Asırlık Çınar” en sık kullanılan metafor olmuştur. "sağlam bir bina, su, anne, bina temeli, Finlandiya eğitim sistemi, hayat, orman" sık kullanılan diğer metaforlardır.

Araştırmada, katılımcıların TES'in var olan durumunu metaforlarla açıklamaları istenmiştir Bu konudaki katılımcı görüşleri, TES'in var olan durumuna ilişkin görüşler teması altında dört alt temada gruplandırılmıştır. Bu temalar Tablo 3 'te yer almaktadır.

Tablo 3: Katılımcıların TES'ni neye benzettiklerine ilişkin oluşturdukları metaforların tema dağ 11 เım

\begin{tabular}{|c|c|c|c|}
\hline Kategoriler & Metaforlar & $\begin{array}{c}\text { Metafor Sayısı } \\
\text { (f) }\end{array}$ & $\begin{array}{c}\text { Katılımeı } \\
\text { Sayısı }\end{array}$ \\
\hline $\begin{array}{l}\text { Reformların sıklığı ve } \\
\text { uzun vadeli sonuç } \\
\text { üretememesi }\end{array}$ & $\begin{array}{l}\text { Kanserli bir vaka (1), Arap saçı (1), } \\
\text { Gelişmeye aday bir şehir (1), } \\
\text { Kervansaray (2), Yapboz (7), Dart tahtası (1), } \\
\text { Hasarlı bir binaya (1), } \\
\text { Kaldırım taşı (1), Mevsimlik Meyve (1), Çocuk (1), } \\
\text { Bukalemun (7), Rotası kayıp gemi (1), Türk dizileri } \\
\text { (1), Çocuk oyuncağı (1), Bumerang (1), Yemek (1), } \\
\text { Doğanın oluşumu (1), Yazboz tahtası (3), İnşaat } \\
\text { (1), Okyanus dalgası (1), Deneme tahtası (1), Ne } \\
\text { yapacağını bilmeyen bir adama (1), Lokomotif (1), } \\
\text { Koşu bandı (1), Pankreas kanseri oluş biri (1), } \\
\text { Ezberci eğitim sistemine (1), Mehteran (1), } \\
\text { Ayarsız bir makas (1), Tutmayan cıvata (1), } \\
\text { Amaçsız bir topluluk (1). }\end{array}$ & 30 & 45 \\
\hline Körelticilik & $\begin{array}{l}\text { Sürekli duran araba (1), } \\
\text { Hazır yemek (1),Yüksek kalorili yemek (1), } \\
\text { Pavlov'un köpeği(1), Bürokratik süreçlere (1), } \\
\text { Fabrika (1), Disiplinsiz kışla sistemi (1) }\end{array}$ & 7 & 7 \\
\hline Karmaşık ve grift yapı & $\begin{array}{l}\text { Çuval (1), Turşu (1), Makine(1), Yanmış } \\
\text { yemek(1), İp yumağı(1), Düzeni kaçmış } \\
\text { Fabrika(1) }\end{array}$ & 6 & 6 \\
\hline Tektipleştiricilik & Fabrika (1), Torna Tezgahı (1) & 2 & 2 \\
\hline Diğer & $\begin{array}{l}\text { Papağan (1) Bisiklet sürücüsünün kullandığı tank } \\
\text { (1) Bilginin sayılarla ifade edildiği bilgi yarışı (1) }\end{array}$ & 3 & 3 \\
\hline
\end{tabular}


Tablo 3'te katılımcıların oluşturdukları metaforların kategorik dağılımı görülmektedir. Bu konuda oluşturulan metaforlar 5 farklı kategoride toplanılmıştır. "Karmaşık ve grift bir hal” kategorisinde 6 eğitimci 6 farklı metafor oluşturmuş, "körelticilik” kategorisinde 7 eğitimci 7 farklı metafor oluşturmuş ve "reformların sıklı̆̆l ve uzun vadeli sonuç üretememesi" kategorisinde ise 45 eğitimci 30 farklı metafor geliştirmiştir. Oluşturulan kategorilere ilişkin katılımcıların orijinal görüş örnekleri şöyledir;

\section{Reformların sıklığı ve uzun vadeli sonuç üretememesi}

E11: “TES, yapboza benzer. Çünkü çok fazla değişiklik yapılmaktadır.”

E12: “TES, kervana benzer. Çünkü alınan kararlar bilimsel süzgeçten geçmeden, alt yapı hazırlanmadan uygulamaya geçilmektedir. "Kervan yolda dizilir” mantı̆̆ ile kararlar alınmakta ve uygulamaya geçilmektedir. Eğitim gibi önemli bir konu ile ilgili projeler işin içine girmeden, bütün hazırlıklar yapılmalıdır”.

E16: “TES, bukalemuna benzer. Çünkü her an değişiyor, başka ülkelerin ĕgitim sistemlerine özenilerek, alt yapı oluşturulmadan, toplumsal yapıya uygun olup olmadığ düşünülmeden ve en önemlisi çocukların gelişim özellikleri ihmal edilerek tasarlanıp uygulaniyor."

E55: “TES, tutmayan cıvataya benzer. Çünkü sık sık değişiklikler yapılmaktadır. Yeterince araştırılıp yeterli ve gerekli değerlendirmeleri yapılmayan programlar uygulanmaktadır. Kısa süreler sonunda da uygulamadan kaldırılmaktadır ya da değişiklikler yapılmaktadır."

E60: “TES, mehterana benzer. Çünkü ileriye doğru çok küçük değişmeler sergilenmektedir. Sürekli hareketli olmasına rağmen yerinde saymaktadır.” 


\section{Körelticilik}

E4: “TES, sürekli duran bir arabaya benzer. Çünkü insanların beyinleri donanımlıdır. Fakat yanlış ĕ̆itim sistemleri bu donanımların ortaya çıkmasını engellemektedir. Türk ĕ̆itim sistemi de böyledir.”

\section{Karmaşık ve grift yapı}

E57: “TES, düzeni kaçmış fabrikaya benzer. Çünkü eğitimde istenilen ürünlerin elde edilmesi için bütün çarkların uyum içinde çalışması gerekir. Dişlilerden bir tanesi uyumsuz olursa fabrika karmakarışık bir hal alır. Türk eğitim sistemi de bu şekilde karmakarışıktır.”

\section{Tektipleştiricilik}

E62: "Türk eğitim sistemi fabrikaya ya da torna tezgahına benzer. Çünkü üniversite ve liseye gidebilmek için sınav yeterliliğinin arandığ bir sistemde öğrenciler, çizilen sinırların dışına çıkamamaktadır. Hayatlarının sınavda çıkacak sorulara endeksli olduğunu söylemek yanlış olmaz. Öğrencilere ham madde, okul ve eğitim sistemine fabrika, sonuca ise ürün gözüyle bakılıyor. Ama dikkatimizi çeken kısım ise hammaddeden hep aynı formata sahip ürünlerin üretilmesidir. Bu farklı yapıda olan insanların formatının doğasına ya da yaratılışına aykırıdır."

Araştırmada, katılımcılardan TES' in olması gereken durumu metaforlarla açıklamaları istenmiştir. Bu konudaki katılımcı görüşleri, TES'in olması gereken durumuna ilişkin görüşler teması altında 10 alt temada gruplandırılmıştır. Bu temalar aşağıda Tablo 4 'te yer almaktadır.

Tablo 4: Katılımcıların TES'nin neye benzemesi gerektiğine ilişkin oluşturulan metaforların Tema Dağılımı

\begin{tabular}{|c|c|c|c|}
\hline Kategoriler & Metaforlar & $\begin{array}{l}\text { Metafor Sayısı } \\
\text { (f) }\end{array}$ & $\begin{array}{c}\text { Katılımcı } \\
\text { Sayısı }\end{array}$ \\
\hline $\begin{array}{l}\text { Devamlılık ve } \\
\text { sağlamlık }\end{array}$ & $\begin{array}{l}\text { Sağlam bir bina (4), Berrak su (1), Kale (1), Asırlık } \\
\text { Çınar (7), Güçlü bir birey (1), Soluksuz bir roman (1), } \\
\text { Çocuk (1), Bir ağacın büyümesi (1), Fabrika (1), } \\
\text { Öğretmenin daha fazla merkezde olduğu bir sistem (1), } \\
\text { Avrupa'nın oturmuş eğitim sistemi (1), Planlı (1), } \\
\text { Hacıyatmaz (1), Uzay mekiği (1), Yeni yapılan bir bina } \\
\text { (1), Bina temeli (2), }\end{array}$ & 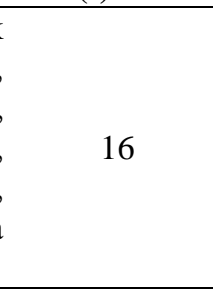 & 26 \\
\hline Bireyselleştiricilik & $\begin{array}{l}\text { Anne (2), Hayat (1), Orman (2), Farklı tatların ortaya } \\
\text { çıtığ1 mutfak (1), }\end{array}$ & 4 & 6 \\
\hline Yararlılık & $\begin{array}{l}\text { Finlandiya eğitim sistemi (2), Bilim (1), Arı (1), } \\
\text { Geridönüşüm (1), Keyif alınan bir oyun (1) }\end{array}$ & 5 & 6 \\
\hline Özgürleştiricilik & $\begin{array}{l}\text { Hayat (1), Araştırıcı-Deneyimleyici (1), Osmanlı'nın } \\
\text { ilk yılları (1), Su (1), Bir ağacın dalları (1) }\end{array}$ & 5 & 5 \\
\hline Ahenklik & $\begin{array}{l}\text { Ekolojik dengenin olduğu bir sistem (1), İnsan (1), } \\
\text { Uyumlu dişlilerden oluşan bir saat (1), Sağlıklı bir insan } \\
\text { vücudu (1). }\end{array}$ & 4 & 4 \\
\hline $\begin{array}{l}\text { İhtiyaçlara cevap } \\
\text { verebilirlik }\end{array}$ & $\begin{array}{l}\text { Su (1), Ahtapot (1), Dünya vatandaşı (1), İyi ayarlanmış } \\
\text { makas (1) }\end{array}$ & 4 & 4 \\
\hline
\end{tabular}


YYÜ Eğitim Fakültesi Dergisi (YYU Journal of Education Faculty), 2021; 18(1)522-546,http://efdergi.yyu.edu.tr,

Nitelikli Formula sürücüsünün kullandığı arazi aracına (1),

Öğretmen Parmak izi(1), Avrupa Birliği üyesi ülkelerin eğitim sistemi (1)

\begin{tabular}{llcc}
\hline Yenilikçilik & $\begin{array}{l}\text { Kültürel sermaye (1), Yaşadı̆̆ çevreye adapte olabilen } \\
\text { canlılar (1) }\end{array}$ & 2 & 2 \\
\hline Bilimsellik & Güneş (1), Çocukların dostu (1), & 2 & 2 \\
\hline $\begin{array}{l}\text { Müfredatın } \\
\text { sadeliği }\end{array}$ & İnsan metabolizması (1), İşlevsel (1) & 2 & 2 \\
\hline Diğer & $\begin{array}{l}\text { Yapılandırmacı ve devlet politikası (1), Finlandiya } \\
\text { eğitim sistemi (1), Sevgi (1) }\end{array}$ & 3 & 3 \\
\hline & Toplam & 50 & 63 \\
\hline
\end{tabular}

Tablo 4'de katılımcıların verdikleri yanıtlara ilişkin metaforların kategorik dağılımı görülmektedir. Eğitimcilerin bu ifadeye ilişkin metaforları 10 kategori altında toplanmıştır. "Ahenk" kategorisinde 4 eğitimci 4 farklı metafor; "bilimsellik" kategorisinde 2 eğitimci 2 farklı metafor; "bireyselleştirici" kategorisinde 4 eğitimci 6 farklı metafor; "ihtiyaçlara cevap veren" kategorisinde 4 eğitimci 4 farklı metafor; "müfredatın sadeliği” kategorisinde 2 eğitimci 2 farklı metafor; "nitelikli öğretmen” kategorisinde 3 eğitimci 3 farklı metafor; "devamlılık ve sağlamlık" kategorisinde 26 eğitimci 16 farklı metafor; "özgürleştiricilik” kategorisinde 5 eğitimci 5 farklı metafor; "yararlılık" kategorisinde 5 eğitimci 6 farklı metafor; "yenilikçilik" kategorisinde 2 eğitimci 2 farklı metafor; ve son olarak "diğer" kategorisinde 3 eğitimci 3 farklı metafor geliştirmiştir. Oluşturulan kategorilere ilişkin katılımcıların orijinal görüş örnekleri şöyledir;

\section{Devamlılık ve sağlamlık}

E9: “TES, kale gibi olmalıdır. Çünkü yılların keşmekeşliğine, zelzelesine, sel felaketlerine rağmen dimdik ayakta durabilen ama bir o kadar da günün şartlarına uyum sağlayabilen bir sistem olmalıdır. Hiçbir görüşün, düşüncenin etkisinde kalmadan mesleki ve akademik gelişmeye önem veren bir sistem olmalıdır."

E16: “TES, asırlık bir çınar gibi olmalıdır. Kim ülkeyi yönetirse yönetsin değişmez ilkeler benimsenmeli ve uygulanmalıdır."

\section{Bireyselleştiricilik}

E24: “TES, orman gibi olmalıdır. Çünkü içerisinde farklı ăgaç türleriyle uyum içerisinde ve sürekli kendini yenileyen dinamik bir yapıya sahip olmalıdır. Tüm orman ağaçlarını aşılayarak ormanı tek tip bir ağaç modeline dönüştürmek, her gün aynı meyveyi yemeye benzer. Farklı tatlara da ihtiyaç vardır. Bunu da ilköğretim çağından itibaren ögrencilerin yetenekli olduğu alanlar keşfedilerek, o dalda gelişimi desteklenmelidir.” 
YYÜ Eğitim Fakültesi Dergisi (YYU Journal of Education Faculty), 2021; 18(1)522-546,http://efdergi.yyu.edu.tr,

\section{Yararlılık}

E12: “TES, arı gibi olmalıdır. Çünkü arı hem çok faydalı hem de çok çalışkandır. Ĕ̆itim de bireye hem yararlı olmalı hem de sürekli çalışma azmi aşılamalıdır."

\section{Özgürleştiricilik}

E50: “TES, bir ăgacın dalları gibi olmalıdır. Çünkü mevcut ĕgitim sistemi, bu eksikliklerden muzdariptir. Bir ăgacın dalları gibi ă̆acın kökünden aldığı her şeyi bütün ăgaca yaymalıdır. Bu dalların biri bilim, biri sanat, biri ahlak olmalıdır. Okuyan, kendini ifade edebilen, sorgulayan bireyler yetiştirilmelidir."

\section{Ahenklik}

E61: “TES, sağllklı bir insan vücudu gibi olmalıdır. Çünkü sağllklı olan vücutta, organların çalışması rahat ve sıkıntısızdır. Organların çalışmasındaki iş bir zincirin halkaları gibidir. Halkalardan birinin kompası diğerlerini de olumsuz etkiler. Ĕgitim sistemimizde de halkalar birbirine tutturulmalı ve daha dinç, sağlıklı, hedeflerine ulaşabilen, aldiğı kararlarda bütünü görebilen, sonuçları kestirebilen, çağa ayak uydurabilen bir yapı olmalıdır.”

\section{İhtiyaçlara cevap verebilirlik}

E63: “TES, ahtapot gibi olmalıdır. Birey her yönden sartp sarmalayan bir sistem olmalıdır. Ahtapotun bir kolu araştırmaya yöneltirken, diğer kolları okumaya, merak etmeye, incelemeye, geleceği görmeye, muhakemeye ve yorumlamaya yönelik olmalıdır. Bireylerin ihtiyaçlarına cevap verici nitelikte bir eğitim sistemi olmalıdır."

\section{Nitelikli öğretmen}

E51: “TES, Formula sürücüsünün kullandı̆̆ı arazi aracı gibi olmalıdır. Çünkü eğitim süreci boyunca her an farklı koşullar ve olumsuzluklarla karşılaşılabilir. Bu sorunları yerinde ve zamanında tespit eder ve alacă̆ımız kararlarla, yapacă̆ımız manevralarla iyi ve kalifiye bir ögretmen çözebilir. Bu nedenle; öğretmen yetiştirme sistemimiz baştan ele alınmalıdır. Eğitim fakültelerinde öğrenciler ümitsizce, son çare olarak yerleşmekten vazgeçilmelidir. Öğretmen yetiştiren kurumlara sınavlarda başka bir yere gidemediği için yerleşen ögrencilerin yönelimini engelleyen düzenlemeler yapılmalıdır. Kısacası ögretmenlik gerçek anlamda bir saygınlık ve uzmanlık mesleği haline getirilmelidir."

\section{Yenilikçilik}

E2: “TES, yaşadiğı çevreye adapte olabilen canlılar gibi olmalıdır. Çünkü sistemimiz toplumun, çă̆ın geleneklerini karşılamamakta, üzerinde yapılmaya çalışılan değişiklikler

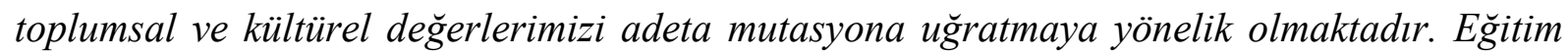


sisteminin genlerinde bir değişiklik olmadan çağın gereklerine uyum sağlayabilen, yenilikçi, dinamik bir yapı özelliği taşımalıdır.,

\section{Bilimsellik}

E55: “TES, güneş gibi olmalıdır. Çünkü bilimsel gerçeklerin rehberliğinde araştırmaya, eleştirmeye, sorgulamaya, ...vb. özelliklere sahip olabilecek ĕgitim öğretim programları uygulanmalıdır. Bu uygulanırken ülkemizin gerçekleri de göz önünde bulundurulmalıdır. Kendi coğrafyamızın değerleri ve insanlarımızın sosyo-kültürel birikimleri çerçevesinde oluşturulmalıdır. Programlarımız ve eğitim öğretim çalışmalarımız güneş gibi sürekli insanlarımızı aydınlatmalıdır."

\section{Müfredatın sadeliği}

E48: “TES, insan metabolizması gibi olmalıdır. Çünkü müfredat çok yoğundur. Metabolizmayı gereğinden fazla beslersek mutlaka anormallikler ortaya çıkar. Müfredat herkesi, her disiplinde uzman yapmaya çalışmaktadır. Bunun yerine daha sade müfredatla özel alanlara yönlendirilmelidir.”

\section{Sonuç ve Tartışma}

$\mathrm{Bu}$ çalışmada eğitimcilerin TES'nin mevcut ve idealine ilişkin algıları metaforlar yardımıyla ortaya konulmaya çalışılmıştır. Türk eğitim sisteminin mevcut durumuna yönelik belirtilen metaforlar; reformların sıklı̆̆l ve uzun vadeli sonuç üretememesi, körelticilik, karmaşık/grift bir yapı ve tektipleştiricilik şeklinde dört farklı kategoride toplanmıştır. $\mathrm{Bu}$ konuda eğitimcilerin Türk eğitim sisteminin sürekli değişkenlik göstermesine vurgu yapmaları dikkat çekmektedir. Türk eğitim sisteminin partiler/hükümetler üstü bir yapıda olmaması, politikalardaki istikrarsızlıklar, merkezi teşkilat düzeyi üst düzey yöneticilerde sık yaşanan değişimler ya da yer değiştirmeler ve bunun sonucu olarak eğitimde ulusal sınavlar başta olmak üzere bütün okul kademelerinde uygulamalar ve programlarda yapılan değişikliklerin katılımcıların büyük çoğunluğunun Reformların sıklı̆̆ ve uzun vadeli sonuç üretememesi kategorisinde toplanmasına sebep olduğu söylenebilir. Çalışmadan elde edilen bu bulgular, literatürde yer alan bazı çalışmalarca (Kutlu Abu, Bacanak ve Gökdere, 2016; Taşdemir, 2015; Yeşil ve Şahan, 2015) desteklenmektedir.

Yeşil ve Şahan (2015) eğitim anlayışı ve eğitim programlarının niteliğinin oldukça önemli bir sorun olduğunu ifade ederek; eğitime bakış açısı bir başka ifade ile paradigma değişikliğinin eğitimin niteliği ile ilgili sorunlara çözüm oluşturmadığını ileri sürmektedir. Kutlu Abu, Bacanak ve Gökdere (2016), yaptıkları araştırmada eğitim sisteminde değişen eğitim paradigmalarına rağmen sistemde var olan sorunların çözülemediği ve varlığını 
sürdürdüklerini vurgulanmıştır. Taşdemir (2015) ise, sistemin sürekli değişmesi, ezberci eğitim anlayışı gibi sorunlara vurgusu araştırma bulgularıyla örtüşmektedir.

Katılımcıların idealde Türk eğitim sisteminin neye benzemesi gerektiğini nedenleriyle açıkladıkları bu bölümde ileri sürdükleri metaforlar 10 ayrı kategoride toplanmıştır. Devamlılık ve sağlamlık, yararlılık, bireyselleştiricilik, özgürleştiricilik öne çıkan kategorilerdir. Frekansı en yüksek kategori olan reformların sıklığl ve uzun vadeli sonuç üretememesi kategorisindeki sonuçlara paralel olarak devamlılık ve sağlamlık vurgusunun yapılması dikkati çekmekte ve araştırmaya katılanların araştırmada yer alan ifadelere tutarlı cevaplar verdiğini göstermektedir.

Araştırmanın sonuçlarına benzer olarak Kızılkaya (2014) da çalışmasında, her iktidarın eğitim sistemini yeniden düzenlediğini, kendi fikirleri ışı̆̆ında eğitimin içeriği ve amaçlarında müdahalelerde bulunduğunu, eğitim sistemlerinde gerçekleştirilen bu ideolojik değişimlerin sistemin felsefi bir temele oturtulmasını olanaksız hale getirdiğini ve sistemi problemli bir ip yumağına dönüştürüldüğünü ifade etmiştir. Bu sebeple TES'in ideolojik ve politik temelli olmasından kaynaklı felsefi bir temelinin olmadığını vurgulayan araştırmacı, bu durumun da sürekli değişen bir eğitim sistemine zemin oluşturduğu sonucuna ulaşmıştır. Ayrıca eğitim sisteminin sağlam bir bilimsel ve felsefi temele oturtulmaması eğitim sisteminin politik ve ideolojik etkiler karşısında zayıf olduğunu da vurgulamıştır. Gür ve Çelik'e (2009) göre de; her iktidar başa geldiğinde eğitimde yenilik hareketlerini zorunluluk olarak görmektedir. Dolayısıyla yeterince değerlendirilmeden ve araştırılmadan gerçekleştirilen reformlar eğitimde kaliteyi düşürmektedir. Eğitim reformunu gerçekleştirenler yapılan reformların eğitim sisteminde nasıl bir değişime neden olacağını hesaba katmadıkları gibi toplumun geleceğini nasıl etkileyeceğine de yeterince önem vermemektedir. Buradan hareketle eğitim sistemindeki sorunların temelinde siyasetin gölgesinde yapılan eğitim politikalarının yer aldığını söylemek mümkündür. Her iktidar ya da Milli Eğitim Bakanı değiştiğinde, eğitim yapısında değişiklikler yapılmakta, dolayısıyla yürürlükteki yapı etkinlik kazanamadan artıları eksileri tam olarak tespit edilemeden bir yenisinin eklendiği görülmektedir. Bu durum ise eğitim politikalarında bir süreklilik sağlanamamasına ve sistemin doğal olarak bir yapboz tahtasına dönüşmesine neden olmaktadır.

Gedikoğlu (2005) ve Pınar (2016) da yaptıkları çalışmada bu araştırmaya paralel olarak TES'in en önemli sorununun sürekli değişen ve bireylere fayda sağlamaktan ve özgürleştirmekten uzak yapısı olduğunu vurgulamaktadırlar. Bu nedenle, TES'in, 21. yüzyıl becerilerini kapsayacak biçimde günümüz bilgi çağının ihtiyaçlarını göre yeniden irdelenip inşa edilmesi, yorumlanması elzem görünmektedir. 
Araştırmada öne çıkan sonuçlara bakıldığında TES'de öğrencilerin bireysel yeteneklerinin göz ardı edildiği dolayısıyla, öğrenci ihtiyaçlarına cevap veren, özgür bir eğitim ortamına sahip olması gerektiği vurgulanmaktadır. Bucuka (2009) çalışmasında öğrencilerin sosyalleşme sürecinde okuldan beklenenin, çocukların potansiyellerinin keşfedilmesi ve yetenekleri doğrultusunda desteklenmeleleri, her bakımdan geleceğe, iş ve meslek hayatına hazırlanmalarıdır.

Toplumlar varlıklarının devamını sağlamak, bütüncül ve tutarlı bir değişim süreci geçirmek adına bu duruma uygun bireyler yetiştirmeyi hedeflemektedir (Bucuka, 2009). Bu amaçla ülkeler kendi ideoloji ve stratejilerine uygun bir eğitim sistemi oluşturma ve bu sistemi uygulama çabası içindedirler. Toplumun görece aydınlanmasına etki eden eğitim sistemi, toplumu değiştirip geliştirmektedir. Bu etkiden faydalanmak adına gelişmiş toplumlardaki eğitim sistemlerinin analiz edilerek, geniş bir bakış açısıyla yaşanılan problemlere etkili çözümler üretilmelidir.

Gelişmekte olan bir ülke olarak Türkiye'de milli olan eğitim sisteminin özel ve genel hedefleri 1şı̆̆ında bir yapılanma doğrultusunda eğitim faaliyetleri devam ettirilmektedir. Türk eğitim tarihi incelendiğinde eğitim sisteminin bazı dönemlerde Batı'daki uygulama ve politikaların etkisinde kaldığı ve iyi işleyen, milli bir eğitim sistemi geliştirilemediği açıkça fark edilmektedir. Eğitim alanında Cumhuriyetin kuruluşundan günümüze kadar, geliştirme ve iyileştirme çabalarına yönelik adımlar atılmış olsa da, eğitim sistemindeki problemlerin süreğen bir yapıya büründüğü bilinmektedir. TES, genellikle yabancı ülkelerin eğitim sistemlerinin etkisinde kalmasından ve milli özelliklerden mahrum olmasından dolayı Türkiye’ye yararlı olmaktan uzaklaşmış ve problemler daha da karmaşık hale gelmiştir. Bununla birlikte, "eğitim sisteminde toplumsal, siyasal, ekonomik ve kültürel koşullardan kopuk olarak gerçekleştirilen yenilikler, gerçeklikten uzak olduklarından başarısızlı̆̆a mahkûm olmaktadırlar" (Sağ, 2003, s.12).

TES'in ciddi sorunlarından biri eğitimdeki devamlılığın sağlanamamış olmasıdır. Zaman, eğitimde devamlılığın sağlanmasında önemli bir yere sahiptir. Çünkü zaman, insan zihninin art arda sıralanmasıyla toplumsal bir bilinç ve hafıza oluşturmaktadır. Bu anlamda tarihin de bu toplumsal bilincin ortaya çıkmasında ciddi bir yer edindiği söylenebilir. Eğitimde devamlılık, kümülatif bilginin devredilmesiyle oluşur. Bilginin devamlılı̆̆ı da sağlam bir bilinç yapısının ortaya çıkmasını sağlar. Eğitimdeki gelişmelerde devamlılığın sağlanması, düşüncenin oluşumunda çok önemli bir noktadır. Bugün halen eğitimde uzun erimli planlamaların sağlanamaması, bilincin ortaya çıkardığı düşüncenin sözlü ve yazılı ifade 
edilişinin yeterli seviyeye ulaşmamasıyla ilişkilidir. Diğer bir ifadeyle şimdinin geçmişle ilişkisinin kesintili/kopuk olmasıyla alakalıdır. Bu sebeple eğitimle alakalı ortaya konulan her yeni değişiklik üzerindeki tartışmalar tarihsel hafızadan kopuk olması sebebiyle her defasında ilk kez konuşuluyormuş hissiyatı vermekte ve bağlama ilişkin gerçekleştirilen tartışma ve eleştiriler bir kısır döngüye sebep olmaktadır.

Mazlum (2019) eğitim sistemindeki kısır döngüyü kapsamlı biçimde ortaya koyduğu çalışmasında yasal düzenlemelerden, ulusal sınavlara, eğitimin kapsamından okuma-yazma gibi temel becerilere kadar hemen her alanda her seferinde başa dönüldüğü bir döngüden söz etmektedir. Mazlum (2019) TES'nde kısır döngünün en fazla politika oluşturma ve sürekli değişiklikler boyutunda yaşandığına, eğitim sistemindeki kısır döngünün merkez politika yapıcıları başta olmak üzere genel itibariyle okul dışı kaynaklı olduğuna araştırma sonuçlarında yer vermiştir.

Araştırmada Türk eğitim sisteminin çok sık değiştiği, karmaşık bir yapıda olduğu, bireyi köreltici ve tektipleştirici olması gibi olumsuz nitelikteki metaforlar ileri sürülmüştür. Türk eğitim sisteminin s1k s1k değişimler geçirmesi, eğitimde devamlılığın oluşmasını engellemektedir. Zamanla büyük emeklerle oluşturulan yapıyı yıkarak yerine sonuçları hakkında kestirimde bulunulamayan yeni uygulamalara geçilmesi Türk eğitim sisteminin uzun erimli bir felsefesinin olmadığı hissini oluşturmakta, eğitimcilerin eğitime olan inançlarına zarar vermektedir. Çalışanlarının inanmadığı bir eğitim yapısı eğitime vurulacak en büyük darbelerden biridir. Değişimin ve kimi zaman da dönüşümün çağın zorunlu kıldığı durumlar olduğu açıktır fakat eskiyi yani "değerliyi” yıkarak değil onun üzerine inşa ederek onun eksiklerini kapatma anlayışıyla yaklaşmak elzemdir. Milli Eğitim Bakanlığı gibi büyük bir örgütün politikalarını hızlı, köktenci ve yazboz tahtasını andıracak günü kurtarmaya yönelik uygulamalara yönelmesi, eğitim ve öğretimin etkililiğini zorlaştırmaktadır.

Türk eğitim sisteminin nasıl olması gerektiği konusunda dikkat çeken metaforların devamlılık ve sağlam yapı, faydacılık, bireyselleştiricilik ve özgürleştiricilik kategorilerinde toplandığı görülmektedir. Özellikle Türk eğitim sisteminin devamlılık göstermesi ve sağlam bir yapıda olması gerektiği vurgusu eğitim sisteminde yapılan palyatif değişikliklerin eğitimciler üzerindeki negatif yansımasıdır. Bu bakımdan aynı zamanda önemli bir uyarı niteliğindedir.

Ülkeler nezdinde oldukça önemli olan eğitim sistemi; çağa uygun nitelikte insan yetiştirmekte ve eldeki kaynakların daha verimli bir şekilde kullanılmasında çok büyük paya sahiptir. Böylesine önem arz eden sistemin çalışması da tesadüflere bırakılmamalıdır. Taymur’a göre (2010, s.1) eğitim kurumlarının bu sorumluluklarını yerine getirme düzeylerinin önceden 
YYÜ Eğitim Fakültesi Dergisi (YYU Journal of Education Faculty), 2021; 18(1)522-546,http://efdergi.yyu.edu.tr,

belirlenmiş birtakım standartlara göre tespit edilmesi; sistemin işleyişi ile ilgili dönüt sağlamak, düzeltme ve geliştirme çalışmalarını planlayıp uygulayabilmek için büyük önem taşımaktadır. Eğitim kurumlarının sorumluluklarını yerine getirip getirmediklerinin kontrolü ve elde edilen dönütler doğrultusunda gelişmeye dönük stratejilerin belirlenmesi ile mümkün olabilmektedir.

\section{Öneriler}

Araştırmanın bulguları doğrultusunda;

- Eğitim kurumunun, siyaset kurumunun dönemsel politik aracı olmaktan kurtulması, her türlü ideolojinin üstünde, bir devlet politikası haline dönüştürülmesi;

- Türk eğitim sisteminin, öğrencilerin bireysel yeteneklerini keşfedip, geliştirecek daha özgür ortamlar sağlaması;

- Değişimlerin mevcut yapıya entegre edilmek suretiyle onu güçlendirecek ve ileri taşıyacak şekilde planlanması önerilmektedir.

\section{Makalenin Bilimdeki Konumu}

Eğitim Bilimleri Bölümü/Eğitim Yönetimi

\section{Makalenin Bilimdeki Özgünlüğü}

Türk Eğitim Sistemi’nin sorunlarını ortaya koymaya yönelik yapılan çalışmalar incelendiğinde; sistemin içerisinde aktif olarak yer alan öğretmenler ile akademisyenlerin bir arada görüşlerini ortaya koyan bir çalışmaya rastlan(a)mamıştır. Sisteme dair çıktılar, sistemin içerisinde aktif olarak yer alan eğitim çalışanlarından alınan dönütler ve sistemin sonunda elde edilen ürünlerin değerlendirilmesi ile elde edilebilir. Sistemin bileşenlerinden olan üniversitelerin eğitim fakültelerinde görev yapan akademisyenler ile okullarda görev yapmakta olan öğretmenlerden alınan dönütlerin, uygulayıcılar ve araştırmacılar için yol gösterici olabileceği düşünülmektedir. 


\section{Kaynaklar}

Ankara Üniversitesi Çalıştay Raporu (2004). Eğitim bilimleri bakış açısıyla eğitimin güncel sorunları ve çözüm önerileri. İçinde Haktanır, G., Dinçer, Ç., Turcan, İ., Küçükturan, G. ve M. Şen, (Edt.). Eğitim Bilimleri Bakış Açısılla Eğitimin Güncel Sorunları ve Çözüm Önerileri. Ankara: Ankara Üniversitesi Eğitim Bilimleri Fakültesi Yayınları

Aydoğdu, E. (2008). İlköğretim okullarındaki öğrenci ve ögrretmenlerin sahip oldukları okul algıları ile ideal okul algılarının metaforlar (mecaz) yardımıyla analizi, (Yayımlanmamış Yüksek Lisans Tezi). Osmangazi Üniversitesi Fen Bilimleri Enstitüsü, Eskişehir.

Balc1, A. (2006). Eğitimde örgüt yapısı ve yönetim süreci. Komisyon (Ed.). Türk eğitim siteminde yeni paradigma arayışları (s.248-268). Ankara: Eğitim-Bir-Sen Yayınları.

Bucuka, Y. (2009). Ĕ̆gitim sosyologlarının Türk ĕgitim sistemine ilişkin görüşleri, (Yayımlanmamış Yüksek Lisans Tezi). İnönü Üniversitesi Sosyal Bilimler Enstitüsü, Malatya.

Gedikoğlu, T. (2005). Avrupa Birliği sürecinde Türk Eğitim Sistemi: sorunlar ve çözüm önerileri. Mersin Üniversitesi Eğitim Fakültesi Dergisi, 1 (1), 66-80.

Gelbal, S. ve Kelecioğlu, H. (2007). Öğretmenlerin ölçme ve değerlendirme yöntemleri hakkındaki yeterlik algıları ve karşılaştıkları sorunlar. Hacettepe Üniversitesi Eğitim Fakültesi Dergisi, 33, 135-145.

Guba, E. G., ve Lincoln, Y. S. (1982). Epistemological and methodological bases of naturalistic inquiry. Educational Communication and Technology Journal-ECTJ, 30(4), 233-252.

Gür, B. S. ve Çelik, Z. (2009). Türkiye'de milli eğitim sistemi: yapısal sorunlar ve öneriler. Ankara: Siyaset, Ekonomi ve Toplum Araştırmaları Vakfı (SETA) Yayınları.

Habacı, İ., Karataş, E., Adıgüzelli, F., Ürker, A. ve Atıc1, R. (2013). Öğretmenlerin güncel sorunları. International Periodical for the Languages, Literature and History of Turkish orTurkic, 8(6), 263-277.

Karasar, N. (2016). Bilimsel araştırma yöntemi. Ankara: Nobel Yayınları.

Kızılkaya, H. (2014). Postmodern felsefe ışı̆̆ııda Türk ĕgitim sistemi sorunlarının değerlendirilmesi, (Yayımlanmamış Yüksek Lisans Tezi). Afyon Kocatepe Üniversitesi Sosyal Bilimler Enstitüsü, Afyon. 
YYÜ Eğitim Fakültesi Dergisi (YYU Journal of Education Faculty), 2021; 18(1)522-546,http://efdergi.yyu.edu.tr,

Kutlu Abu, N., Bacanak, A. ve Gökdere, M. (2016). Öğretmen adaylarının Türk eğitim sisteminin sorunlarına ilişkin görüşlerinin incelenmesi. Amasya Üniversitesi Ĕ̌gitim Fakültesi Dergisi, 5(1), 287-307.

Lakoff, G. ve Johnson, M. (2005). Metaforlar: Hayat, anlam ve dil (Çev. G. Y. Demir). İstanbul: Paradigma Yayınları.

Mazlum, M. M. (2019). Yöneticilerin ve ögrretmenlerin görüşlerine göre ĕgitim sisteminde kısır döngü, (Yayımlanmamış Doktora Tezi). Ankara Üniversitesi Eğitim Bilimler Enstitüsü, Ankara.

Miles, M. B. ve Huberman, A. M. (2014). Qualitative data analysis: an expanded source book. Thousand Oaks, CA: Sage Publications, Inc.

Özdemir, F. ve Kaplan, A. (2017). Öğretmen adaylarının bakış açısından Türk eğitim sisteminin sorunları ve bu sorunlara yönelik çözüm önerileri. Turkish Studies, 12(28), 577-592.

Patton, M. Q. (1987). How to use qualitative methods in evaluation. Newbury Park, CA: Sage Publications, Inc.

Patton, M. Q. (2002). Qualitative research and evaluation methods. Newbury Park, CA: Sage Publications, Inc.

Pınar, Ş. (2016). Günümüz Türk eğitim sistemi ve öğrenci profili (Kırıkkale örneği), (Yayımlanmamış Yüksek Lisans Tezi). Kırıkkale Üniversitesi Eğitim Bilimleri Enstitüsü, Kırıkkale

Pratte, R. (1981). Metaphorical models and curriculum theory. Curriculum Inquiry. 11(4), 307320.

Saban, A., Koçbeker, H. N. ve Saban, A. (2006). Öğretmen adaylarının öğretmen kavramına ilişkin algılarının metaforlar yardımıyla analiz edilmesi. Kuram ve Uygulamada Eğitim Bilimleri, 6(2), 461-522.

Sağ, V. (2003). Toplumsal değişim ve eğitim üzerine. Cumhuriyet Üniversitesi Sosyal Bilimler Dergisi, 27(1), 11-25.

Sağlam, M., Özüdoğru, F. ve Çıray, F. (2011). Avrupa Birliği eğitim politikalari ve Türk Eğitim Sistemi’ne etkileri, Yüzüncü Yıl Üniversitesi Eğitim Fakültesi, 8(1), 87-109.

Senemoğlu, N. (2007). Gelişim ögrrenme ve ögrretim: Kuramdan uygulamaya. Ankara: Gönül Yayınc1lık. 
Taşdemir, M. (2015). Öğretmen adaylarının Türk mili eğitim sistemi üzerine algıladıkları sorunlar. Turkish Studies, 10(7), 881-898.

Taşgın, A. ve Sönmez, S. (2013). Öğretmenlik mesleği genel yeterliklerinin sınıf öğretmenleri ve sınıf öğretmeni adaylarının görüşlerine göre değerlendirilmesi. Middle Eastern \& African Journal of Educational Research, 3, 80-90.

Taymur, A. (2010). Türk eğitim sistemi denetim alt sisteminin yeniden yapılandırllmasına ilişkin bir model önerisi (Yayınlanmamış Yüksek Lisans Tezi). Van Yüzüncü Y1l Üniversitesi Sosyal Bilimler Enstitüsü, Van.

Türk, E. (2003). Türk Eğitim sistemi ve yönetimi. Ankara: Nobel Yayınları.

Uğurlu, Z., Kıral, E., ve Kıral, B. (2011). Öğretmen adaylarının Türk eğitim sisteminin sorunlarına ilişkin görüşleri, 20. Eğitim Bilimleri Kurultayı Bildiri Özeti.

Woon, J. ve Ho, Y. (2005). Metaphorical construction of self in teacher narratives. Language and Education, 19(5), 359-379.

Yapıc1, İ. Ü. (2015). Lise öğrencilerinin biyoloji kavramına ilişkin metaforik algıları. Elektronik Sosyal Bilimler Dergisi, 14(55), 139-147.

Yeşil, R. ve Şahan, E. (2013). Öğretmen adaylarının Türk eğitim sisteminin en önemli sorun, neden ve çözüm yollarına ilişkin algıları, Ahi Evran Üniversitesi Kırşehir Eğitim Fakültesi Dergisi, 16(3), 123-143.

Yıldırım, A. ve Şimşek, H. (2008). Sosyal bilimlerde nitel araştırma yöntemleri. Ankara: Seçkin Yayıncılık.

Yılmaz, K. ve Altınkurt, Y. (2011). Öğretmen adaylarının Türk eğitim sisteminin sorunlarına ilişkin görüşleri, Uluslararası İnsan Bilimleri Dergisi, 8(1). 942-973.

\section{Summary}

\section{Statement of Problem}

Education is not only a process that regulates a person's life but also an important system that regulates social structure. Thus, social groups, nations or civilizations that evaluate 
education in every aspect and strive to be a society of knowledge and science societies aim to develop collectively. Studies focusing on modernization, regulation, reform, or quality in education are based on the determination of trends in the light of today's educational paradigms via the assessment of the previous and current education systems. As a result of the evaluations, new ideas that are likely to guide the education system should be determined and included in education and training studies (Türk, 2003).

The education system is in an integrated structure through preschool, primary education, secondary education, and higher education subsystems for certain purposes. The education system of Turkey tends to implement European Union education policies in an attempt to increase the quality and efficiency of education (Sağlam, Özüdoğru, \& Çıray, 2011). Although the Turkish education system (TES) has made some improvement and progress through activities within the scope of the European Union harmonization process, there are still some problems that have yet to be resolved. This research aims to examine the perceptions of academics and teachers about the TES through metaphors.

\section{Method}

The research was designed with the method of phenomenology, which is one of the qualitative research methods. The study group was determined via the maximum variation sampling method, one of the purposeful sampling types. The participants of the study are comprised of 54 teachers (from 16 different branches) from 25 schools in the central districts of Van, İpekyolu, Tusba, and Edremit, and 9 academicians from the Faculty of Education of Van Yüzüncü Y1l University. The data obtained via the semi-structured interview form developed by the researchers were analyzed through content analysis.

\section{Findings}

Metaphors created regarding the statement "The Turkish education system is like........ . For, ....” shown in Table 1 reveal that 63 educators have produced 47 different metaphors on this subject. Although the most frequently used metaphors are "chameleon" and "puzzle", "Caravanserai, Factory, Scratchpad" are metaphors used by more than one person. On the other hand, metaphors regarding the statement "Turkish education system should be like.... . For, ... ” are given in Table 2. The table reveals that 63 educators have produced 47 different metaphors. "Centennial Plane Tree” has been the most frequently used metaphor. "A solid structure, water, mother, building foundation, Finnish education system, life, forest” are other frequently used metaphors. 
Table 3 shows the categorical distribution of the metaphors created by the participants. The metaphors created on this subject are collected in 5 different categories. 6 educators have created 6 different metaphors in the "a complex and grift state" category, 7 educators have created 7 different metaphors in the "hebetation" category, and 45 educators have created 30 different metaphors in the "frequency of reforms and failure to produce long-term results" category. On the other hand, the opinions of the participants about the status of TES are grouped in 10 different categories. Table 4 reveals that 4 educators have created 4 different metaphors in the "harmony" category; 2 educators have created 2 different metaphors in the "scientificity" category; 4 educators have created 6 different metaphors in the "individuative" category; 4 educators have created 4 different metaphors in the "meeting needs" category; 2 educators have created 2 different metaphors in the "simplicity of the curriculum" category; 3 educators have created 3 different metaphors in the "qualified teacher" category; 26 educators have created 16 different metaphors in the category of "continuity and resilience"; 5 educators have created 5 different metaphors in the "emancipatory" category; 5 educators have created 6 different metaphors in the "usefulness" category, and; 2 educators have created 2 different metaphors in the "innovation" category; and 3 educators have created 3 different metaphors in the "other" category.

\section{Discussion and Conclusion}

Educators are observed to emphasize that the TES is constantly changing. The lack of a supra-party/governmental structure in the TES, instability in policies, frequent changes or displacements in the central organizational structure, and, especially national exams and changes in the programs as a result of these changes in education at all school levels have led a majority of the participants to gather in the category of "the frequency of reforms and failure to produce long-term results."

Based on the metaphors created by the participants regarding the statement "Turkish education system should be like For, ... “, it is concluded that the system goes through frequent reforms, and thus fails to produce long-term results. Therefore, the emphasis on the continuity of the system is essential. From this point of view, it is possible to say that education policies under the shadow of politics are at the root of the problems in the education system. upon changes in any ranks of the government or the Minister of Education, the educational structure changes, thus, a new one is added before the current structure gains efficiency and before its pros and cons are not fully determined. This leads to a lack of continuity in education policies and the system naturally turns into a scratchpad. Similarly, it is 
YYÜ Eğitim Fakültesi Dergisi (YYU Journal of Education Faculty), 2021; 18(1)522-546,http://efdergi.yyu.edu.tr,

doi:10.33711/yyuefd.919424 Araştırma Makalesi ISSN: 1305-2020

emphasized in the TES that students' individual abilities are ignored, so they should have a free education environment that meets student needs.

In the study, there were negative metaphors suggesting that the TES changes frequently with a complex structure and is blunting and homogenizing the individual. Frequent changes in the TES prevent continuity in education. Over time, destruction of the structure created with great efforts and the switch to new practices whose consequences are unpredictable imply that the TES does not have a long-term philosophy while it harms the beliefs of educators in education. An educational structure without the faith of its employees is one of the biggest blows to education. It is clear that change, and sometimes transformation, are compulsory cases of the era, but it should be essential to approach with the understanding of making up a shortage by building on the old, namely the "valuable", but not by destroying it.

It is seen that the metaphors that stand out about how the TES should be are collected in the categories of continuity and solid structure, usefulness, individuative, and emancipatory. Especially the emphasis that the TES should show continuity and have a solid structure is the negative reflection of the palliative changes made in the education system on educators. In this respect, it is also an important warning. 